Keywords: 12(S)-HETE; tumour microenvironment; lymph endothelial cell migration; MLC2; signal transduction; 3D-intravasation model

\title{
Cancer cell-derived 12(S)-HETE signals via 12-HETE receptor, RHO, ROCK and MLC2 to induce lymph endothelial barrier breaching
}

\author{
Chi Huu Nguyen ${ }^{1}$, Serena Stadler ${ }^{2}$, Stefan Brenner ${ }^{1}$, Nicole Huttary ${ }^{2}$, Sigurd Krieger ${ }^{2}$, Walter Jäger ${ }^{1}$, \\ Helmut Dolznig ${ }^{3}$ and Georg Krupitza*,2 \\ 'Department for Clinical Pharmacy and Diagnostics, Faculty of Life Sciences, University of Vienna, Althanstrasse 14, A-1090 Vienna, \\ Austria; ${ }^{2}$ Clinical Institute of Pathology, Medical University of Vienna, Waehringer Guertel 18-20, A-1090 Vienna, Austria and \\ ${ }^{3}$ Institute of Medical Genetics, Medical University of Vienna, Waehringer Strasse 10, A-1090 Vienna, Austria
}

\begin{abstract}
Background: The arachidonic acid metabolite 12(S)-HETE is suspected to enhance metastatic spread by inducing cancer cell- and lymph endothelial cell (LEC) motility. However, the molecular mechanisms leading to 12(S)-HETE-triggered cell migration are still elusive.
\end{abstract}

\begin{abstract}
Methods: To delineate the signalling pathways involved in 12(S)-HETE-mediated migration, inhibitors against RHO and ROCK, and specific siRNAs downregulating 12(S)-HETE receptor (12-HETER) and myosin light chain 2 (MLC2) were used. The breaching of the endothelial barrier was investigated by an assay measuring tumour spheroid-triggered 'circular chemorepellent-induced defects' (CCIDs), and respective signal transduction was elucidated by western blotting.
\end{abstract}

Results: We provide evidence that 12(S)-HETE phosphorylated (and activated) MLC2, which regulates actin/myosin-based contraction. MLC2 activation was found to be essential for LEC retraction and CCID formation. Furthermore, we show that 12(S)-HETE activated a 12-HETER-RHO-ROCK-MYPT signalling cascade to induce MLC2 function.

Conclusions: Signalling via this pathway is described for this metabolite for the first time. This may provide potential targets for the intervention of metastatic colonisation.

12(S)-HETE was described as the endothelial retraction factor (Honn et al, 1994), which is physiologically secreted by activated macrophages (Rabinovitch et al, 1981) and platelets (Hamberg and Samuelsson, 1974), functioning as a key that unlocks the lymphatic vasculature. In detail, 12(S)-HETE causes the disintegration of the adjacent lymph vessels due to downregulation of VE-cadherin (Vonach et al, 2011) and migration of lymph endothelial cells (LECs) in the opposite direction of the 12(S)-HETE gradient, thereby opening a gate within the vascular wall termed 'circular chemorepellent-induced defect' (CCID). Secretion of 12(S)-HETE is a general mechanism facilitating the transmigration of colon (Senfter et al, 2015) and breast cancer cells (Uchide et al, 2007) through CCIDs. 12(S)-HETE production is also a prerequisite for the development of metastases within lymph nodes and subsequently in distant organs (Kerjaschki et al, 2011). Interestingly, neutrophils, which also use 12(S)-HETE as a key to move through vascular barriers (Rigby et al, 2015), infiltrate and accumulate in the pre-metastatic lung before breast cancer cells arrive (Wculek and Malanchi, 2015). 12(S)-lipoxygenase expression and 12(S)-HETE treatment was shown to induce colon cancer cell migration and correlates with their malignancy (Klampfl et al, 2012). 12(S)-HETE binds to the G-protein coupled receptor 12-HETER (former orphan receptor GPR31) in prostate carcinoma cells and triggers a pro-migratory/invasive cell response (Guo et al, 2011). This tempted us to investigate, whether 12(S)HETE-triggered CCID formation and migration of LECs is

*Correspondence: Professor G Krupitza; E-mail: georg.krupitza@meduniwien.ac.at

Received 31 March 2016; revised 30 May 2016; accepted 2 June 2016; published online 30 June 2016

(c) 2016 Cancer Research UK. All rights reserved 0007-0920/16 
mediated by 12-HETER, and to elucidate the downstream signalling pathway.

\section{MATERIALS AND METHODS}

Antibodies and reagents. Polyclonal rabbit anti-myosin light chain 2 (MLC2) antibody, polyclonal rabbit anti-phospho-Ser19 MLC2 antibody and polyclonal rabbit anti-myosin phosphatase target subunit 1 (MYPT1) were from Cell Signaling (Danvers, MA, USA). Polyclonal rabbit anti-phospho-MYPT1 (Thr696) was from Upstate (Lake Placid, NY, USA). Monoclonal mouse anti- $\beta$-actin (clone AC-15) antibody was from Sigma (Munich, Germany) and polyclonal rabbit anti-GPR31 (12-HETER) antibody from Cayman Chemical (Ann Arbor, MI, USA). Polyclonal rabbit anti-mouse and polyclonal swine anti-rabbit antibodies were from Dako (Glostrup, Denmark). Alexa-Fluor 488 (green) goat-anti-rabbit labelled antibody was purchased from Molecular Probes, Invitrogen (Karlsruhe, Germany).

Y27623, rhosin, blebbistatin and JAK inhibitor (pyridine P6) were purchased from Calbiochem (Darmstadt, Germany) and 12(S)-HETE from Cayman Chemical.

Small interfering RNA-targeting human 12-HETER (GPR31; SMART pool 'ON-TARGET plus', catalogue no.: L-005564-000005), and siRNA-targeting human MLC2 (catalogue no.: L-011087-00-0005) were ordered from Dharmacon (Gene Expression and Gene Editing, GE Healthcare, Lafayette, CO, USA). Nontargeting control (n.t.Co) RNA (Silencer Select Negative Control No. 1 siRNA, catalogue no.: 4390843) was from Ambion (Life Technologies, Carlsbad, CA, USA). All siRNAs were resuspended in RNAse-free water to a $20 \mu \mathrm{m}$ stock.

Cell culture. Human MDA-MB231 and MCF-7 breast cancer cells were purchased from the American Type Culture Collection (ATCC, Rockville, MD, USA) and grown in MEM medium supplemented with $10 \%$ foetal calf serum, $1 \%$ penicillin/streptomycin and $1 \%$ non-essential amino acids (Gibco, Invitrogen). Telomerase immortalised human LECs were grown in EGM2 MV (Clonetics CC-4147, Allendale, NJ, USA). The cells were kept at $37^{\circ} \mathrm{C}$ in a humidified atmosphere containing $5 \% \mathrm{CO}_{2}$. For CCID formation assays, LECs were stained with Cytotracker-Green purchased from Invitrogen.

Spheroid generation. MDA-MB231 cells (input of 6000 cells per spheroid) or MCF-7 cells (input of 3000 cells per spheroid) were transferred to $30 \mathrm{ml}$ serum-free MEM medium containing $6 \mathrm{ml}$ of a $1.6 \%$ methylcellulose solution ( $0.3 \%$ final concentration). One hundred fifty microlitres of this cell suspension was transferred to each well of a 96-well plate (Greiner Bio-one, Cellstar 650185, Kremsmünster, Austria) to allow spheroid formation within $72 \mathrm{~h}$.

CCID assay. The areas that are formed in the LEC monolayer upon contact with tumour spheroids are measured and are therefore a quantitative assay for lymph endothelial barrier breaching (Vonach et al, 2011; Nguyen et al, 2015). The confluent Cytotracker-stained LEC monolayers (LECs were seeded into 24-well plates; Costar 3524, Sigma-Aldrich, Munich, Germany) were pre-treated with indicated inhibitors for $30 \mathrm{~min}$ before tumour cell spheroids were placed on the top. After $4 \mathrm{~h}$ of incubation, the CCID areas in the LEC monolayers underneath the spheroids were photographed using an Axiovert (Zeiss, Jena, Germany) fluorescence microscope to visualise Cytotracker (green)-stained LECs underneath the spheroids. CCID areas were calculated with the Zen Little software 2012 (Zeiss, Jena, Germany). For each condition the CCID size of 24 or more spheroids (unless otherwise specified) was measured.

Confocal microscopy and immunofluorescence analysis. Lymph endothelial cells were seeded in 1 ml EGM 2 MV onto Lab-Tek II chambered coverslips (Nalgen Nunc International, Wiesbaden, Germany) and allowed to grow for 2 days followed by cocultivation with MDA-MB231 spheroids on LEC monolayers. After $4 \mathrm{~h}$ of incubation, cells were washed with ice-cold phosphate buffered saline (PBS) and fixed in 4\% paraformaldehyde for $15 \mathrm{~min}$ at room temperature. Cells were immunostained with anti-phospho-Ser19-MLC2 antibody (dilution 1:50) and analysed by confocal microscopy. For this, cells were washed with PBS and permeabilised with $0.3 \%$ Triton X-100 in PBS for 30 min at room temperature, followed by washing with PBS and blocking with $5 \%$ goat serum in PBS for $1 \mathrm{~h}$. Cells were further incubated with a fluorescence labelled second antibody diluted 1:500 for $1 \mathrm{~h}$ at room temperature in the dark and washed with PBS. Cells were counterstained with DAPI (dilution 1:500000) at room temperature.

Fluorescence intensity was analysed with Image-J software (National Institutes of Health, Bethesda, MD, USA). The results were expressed as 'mean grey value', which were subtracted to background intensity and normalised to analysed area.

Transfection of LEC monolayer. Lymph endothelial cells were seeded in 24-well plate $(1 \mathrm{ml}$ per well) and grown in EGM2 medium. Transfections were performed at $70-80 \%$ confluence. In all $0.75 \mu \mathrm{g}$ siRNA ( $3 \mu \mathrm{l}$ from $20 \mu \mathrm{m}$ stock) and $6 \mu \mathrm{l} \mathrm{HiPerFect}$ Transfection Reagent (Qiagen, Hilden, Germany, catalogue no.: 301705) were mixed in $100 \mu \mathrm{l}$ serum-free medium and incubated for $30 \mathrm{~min}$ at room temperature to allow the formation of transfection complexes. The old medium was replaced by $500 \mu \mathrm{l}$ fresh EGM2 medium and the transfection complexes were added drop-wise to the cells (to a final siRNA concentration of $100 \mathrm{nM}$ ) and incubated for $24 \mathrm{~h}$ at $37^{\circ} \mathrm{C}$. Then, the medium was replaced by fresh medium and cells were incubated for another $24 \mathrm{~h}$ to recover. Transfected LECs were used for CCID assays or to isolate RNA or proteins.

SDS-polyacrylamide gel electrophoresis (PAGE), western blotting and densitometry. SDS-PAGE and western blotting using the indicated antibodies was performed at least in triplicate to facilitate statistical analysis such as described recently (Nguyen et al, 2015). Equal sample loading was controlled by Ponceau-S staining and $\mathrm{B}$-actin immunoblotting. Relative protein expression levels (controls were set to 1 ) were determined and normalised to phospho-protein levels, then to respective total protein expression and finally to $\beta$-actin expression by densitometry.

12(S)-HETE assay. MDA-MB231 and MCF-7 cells were seeded in 6-well plates and grown in $2.5 \mathrm{ml}$ complete MEM medium to $\sim 70-80 \%$ confluence. Cells were serum-starved for $24 \mathrm{~h}$, and then cells were stimulated with $10 \mu \mathrm{M}$ arachidonic acid for $4 \mathrm{~h}$ to facilitate 12(S)-HETE production. The concentration of 12(S)HETE in the cellular supernatant was measured with minor modifications as described previously (Teichmann et al, 2014) using the 12(S)-HETE enzyme immunoassay kit (EIA, \#ADI-900050; Enzo Life Sciences, Lausen, Switzerland). Absorbance was measured with a Wallac 1420 Victor 2 multilabel plate reader (Perkin Elmer Life and Analytical Sciences, Shelton, CT, USA). The concentration of $12(\mathrm{~S})$-HETE in the cellular supernatant was normalised to cell number.

Statistical analysis. For statistical analyses Excel 2013 software and Prism 6 software package (GraphPad, San Diego, CA, USA) were used. The values were expressed as mean \pm s.e.m. and the Student's $t$-test was used to compare differences between controls and individual samples, whereas analyses of variance (one-way ANOVA) was used to analyse treatment groups. Statistical significance level was set to $P<0.05$. 


\section{RESULTS AND DISCUSSION}

MLC2 is required for breast cancer spheroid-triggered LEC retraction. It was demonstrated that MCF-7 cells secrete $12(\mathrm{~S})$ HETE, which is packed into exosomes (Uchide et al, 2007). Here, MDA-MB231 and MCF-7 breast cancer cells produced 12(S)HETE accumulating in the cell culture medium to an average concentration of $111 \mathrm{ng} \mathrm{ml}^{-1}(\sim 347 \mathrm{nM})$ and $54 \mathrm{ng} \mathrm{ml}^{-1}$ $(\sim 162 \mathrm{nM})$ per $1 \times 10^{6}$ cells within $4 \mathrm{~h}$, respectively. At the sites where breast cancer emboli intravasate into the lymphatic vasculature, tumour, cells have to directly contact the endothelial wall and thus the local concentration of 12(S)-HETE in the immediate proximity of adherent LECs must have been severalfold higher than $347 \mathrm{~nm}$ at least in the in vitro setting studied here.
12(S)-HETE at a concentration level of 0.5-1.5 $\mu \mathrm{M}$ induced Ser19phosphorylation of MLC2, which is indicative for the activation of this migration marker (Figure 1A). Therefore, to study the mechanisms of LEC retraction and CCID formation, LECs were further on treated with $1 \mu \mathrm{M} 12(\mathrm{~S})$-HETE.

Activated MLC2 induces F-actin stress fibres and cell mobility (Sun et al, 2013; Murata et al, 2014). Accordingly, knockdown of MLC2 in LECs by siRNA (siMLC2, Figure 1B) attenuated LEC migration and CCID formation, which was triggered by triplenegative MDA-MB231 spheroids (Figure 1C). To test whether this is a general mechanism, hormone-dependent MCF-7 breast cancer cell spheroids were placed on top of LEC monolayers in which MLC2 expression was knocked down and also in the MCF-7/LEC co-culture model the formation of CCIDs was reduced (Figure 1D). Furthermore, the inhibition of MLC2 by $0.75 \mu \mathrm{M}$ blebbistatin
A

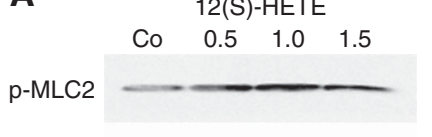

MLC2

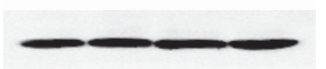

$\beta$-actin

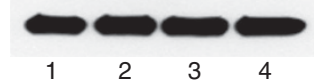

C

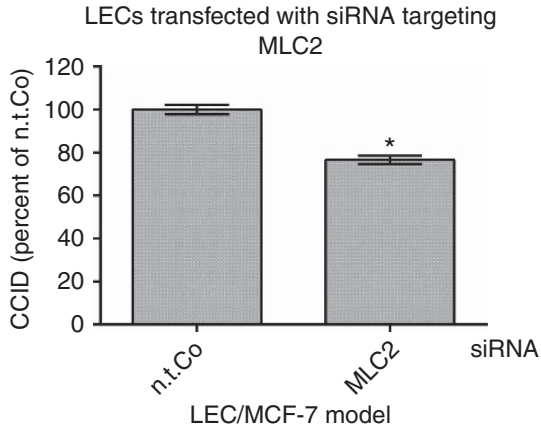

E

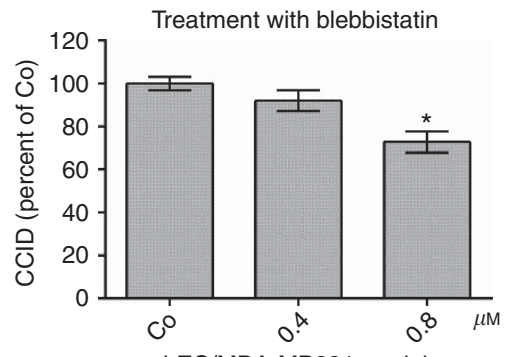

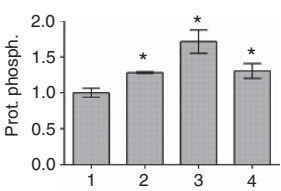

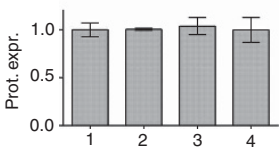

B

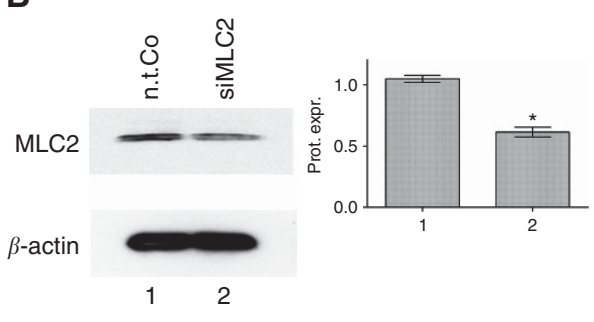

D

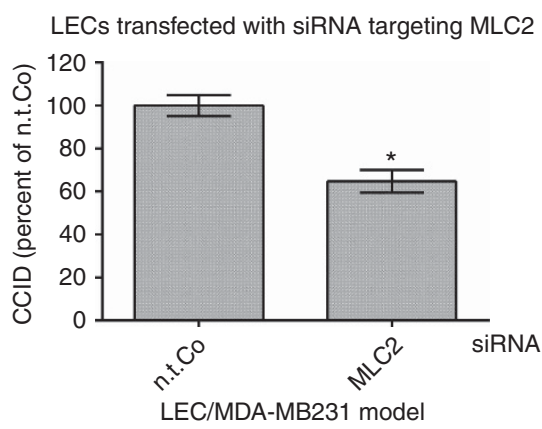

$\mathbf{F}$

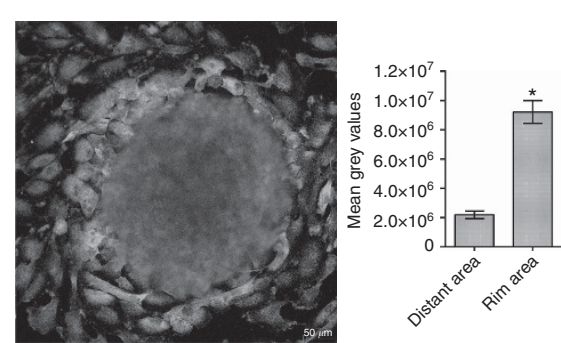

Figure 1. Suppression of MLC2 in LECs inhibits 12(S)-HETE-induced CCID formation. (A) Lymph endothelial cells were stimulated with solvent (DMSO, Co) or 0.5, 1.0 and $1.5 \mu \mathrm{M} 12(\mathrm{~S})$-HETE for $15 \mathrm{~min}$ and the relative phosphorylation (prot. phosph.) and expression (prot. expr.) of MLC2 was quantified (six technical replicates of two independent experiments). The numbers below the bar graphs refer to the respective treatment conditions indicated in the lanes of the blots. (B) Lymph endothelial cells were transiently transfected with either non-targeting RNA (n.t.Co) or siRNA-targeting MLC2 (siMLC2), and protein expression was analysed after $24 \mathrm{~h}$ (six technical replicates of three independent experiments) Error bars indicate means \pm s.e.m., and asterisks significance $(P<0.05$; $t$-test). (C) SiMLC2-transfected LECs were grown to confluence and then, MDA-MB231 spheroids or (D) MCF-7 spheroids were placed on top of confluent LEC monolayers and co-incubated for $4 \mathrm{~h}$. (E) Confluent LECs were pre-treated with 0.4 and $0.8 \mu \mathrm{m}$ blebbistatin or solvent (DMSO, Co) for $30 \mathrm{~min}$ and then MDA-MB231 spheroids were placed on top of LECs monolayers and co-incubated for $4 \mathrm{~h}$ when CCID areas were measured. Error bars indicate means \pm s.e.m. (C, D, 25-34 replicates of three independent experiments each), and asterisks significance ( $P<0.05$; $t$-test or ANOVA). (F) Lymph endothelial cells were grown on coverslips until confluence when MDA-MB231 spheroids were transferred on top of LECs and co-incubated for $4 \mathrm{~h}$ at $37^{\circ} \mathrm{C}$ to allow CCID formation. Laser scanning microscopy demonstrates the increased phosphorylation of Ser19-MLC2 (green; FITC filter, here shown in light grey) at the rim of CCID indicating increased cell mobility. Scale bar: $50 \mu \mathrm{m}$. 

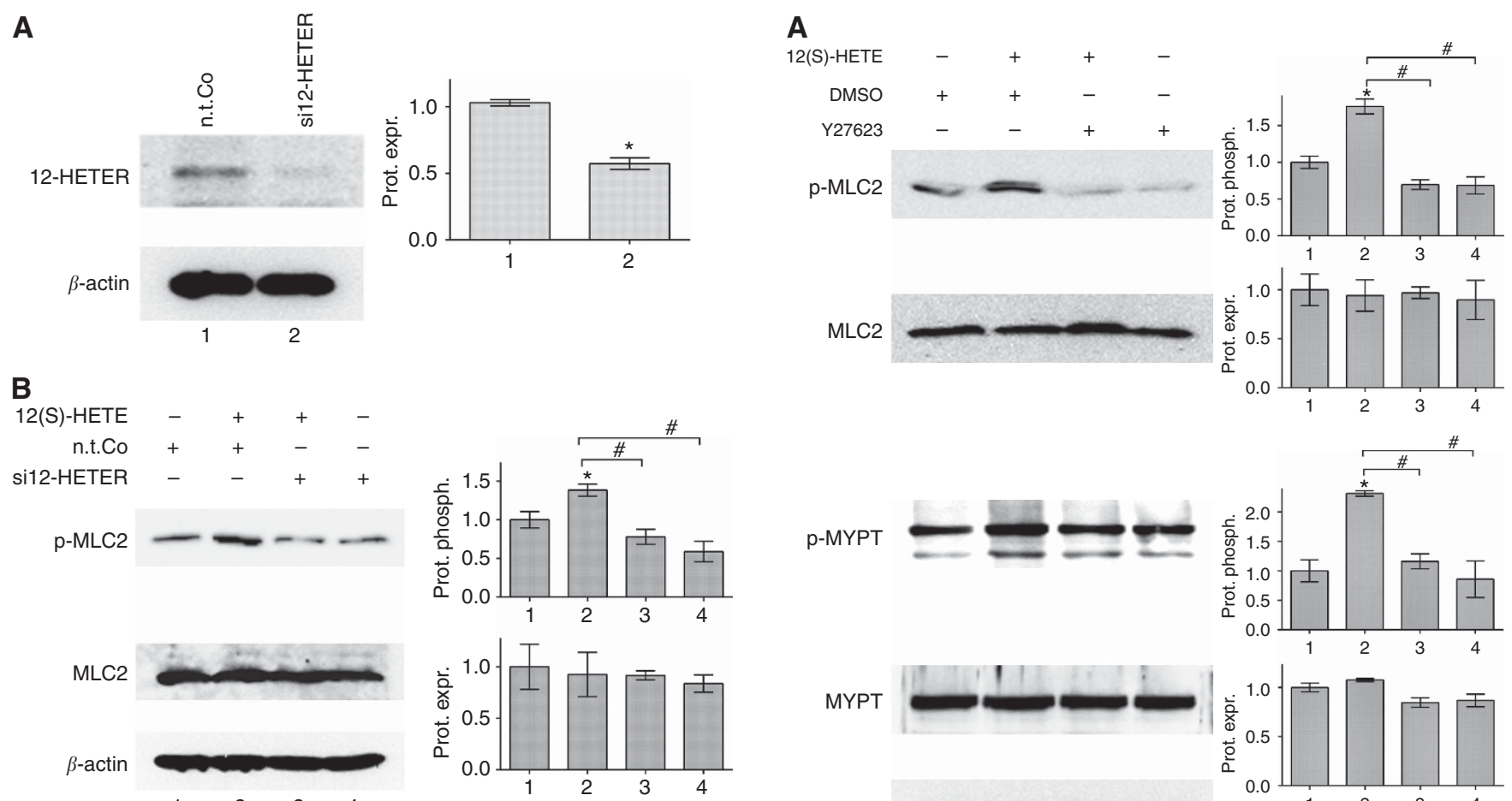

C
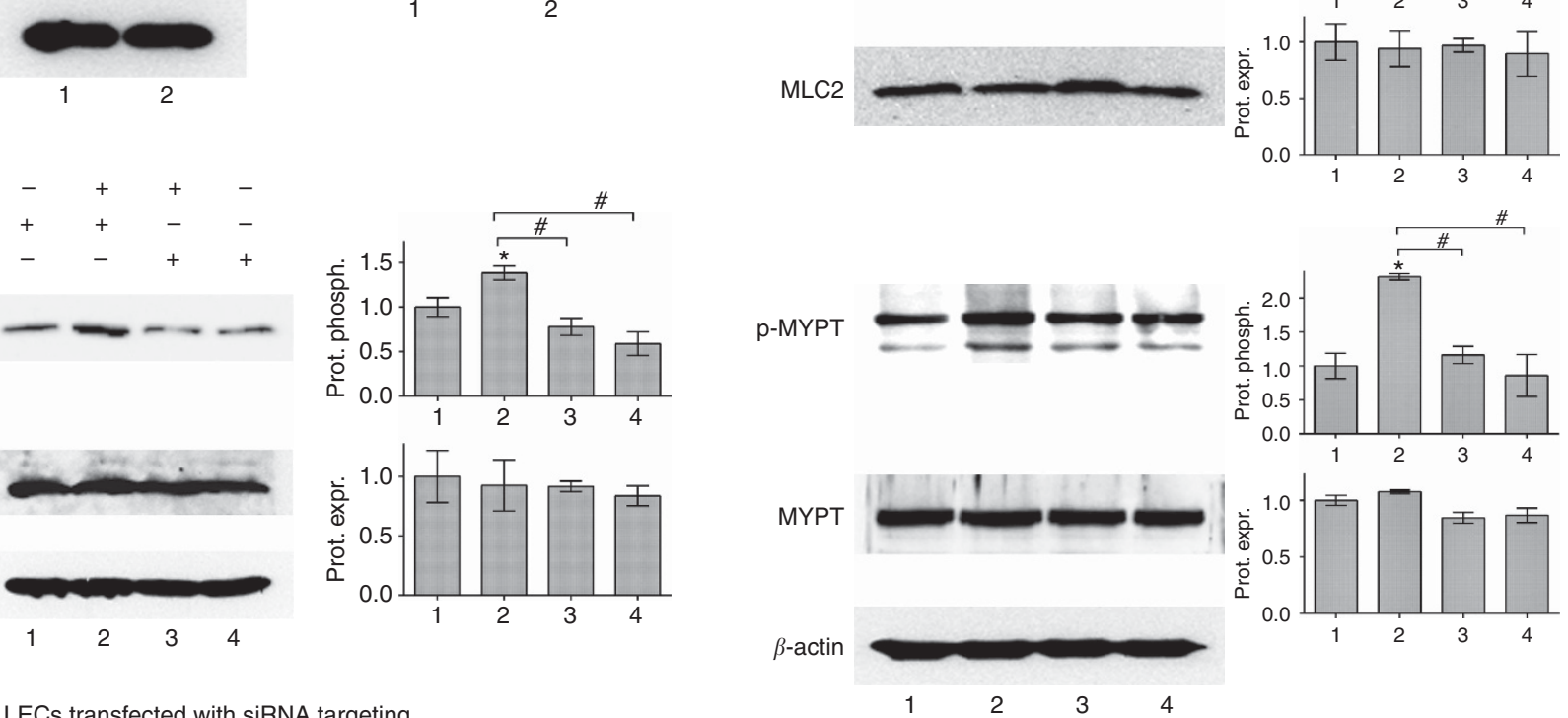

B

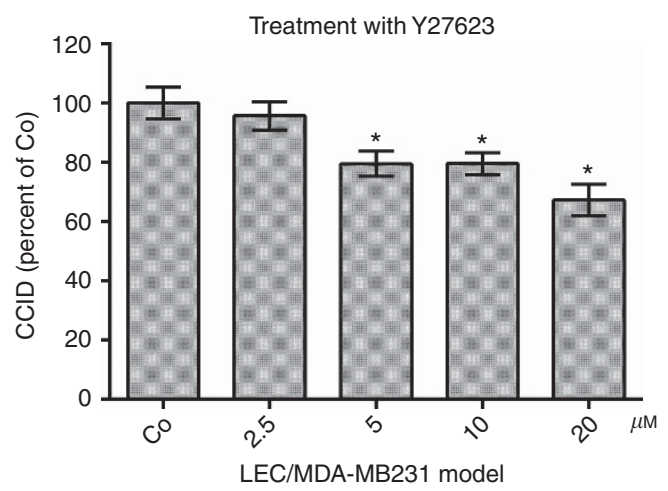

Figure 2. Suppression of 12-HETER in LECs inhibits 12(S)-HETEinduced phosphorylation of MLC2 and CCID formation. Lymph endothelial cells were transiently transfected with either non-targeting RNA (n.t.Co) or siRNA-targeting 12-HETER (si12-HETER) and after (A) $24 \mathrm{~h}$ relative protein expression (prot. expr.) was quantified by densitometry (ten technical replicates of four independent experiments). (B) Si12-HETER-transfected LECs were stimulated with 12(S)-HETE for $15 \mathrm{~min}$ and relative phosphorylation (prot. phosph.) and expression was determined (four technical replicates of two independent experiments). The numbers below the bar graphs refer to the respective treatment conditions indicated in the lanes of the blots. (C) MDA-MB231 spheroids were placed on top of si12-HETER(or n.t.Co) transfected LEC monolayers and co-incubated for $4 \mathrm{~h}$, when CCID areas were measured (31 replicates of three independent experiments). Error bars indicate means \pm s.e.m., and asterisks significance $(P<0.05 ;$ t-test $)$.

(Figure 1E) attenuated CCID formation significantly $(\sim 25 \%)$ and therefore, the data provide evidence that phosphorylation of MLC2 is involved in the signalling pathway that leads to LEC retraction and tumour intravasation in vitro. To avoid nonspecific adverse effects of pharmacological compounds or siRNA (or transfection reagent) their concentrations were kept as low as possible. Immunofluorescence confirmed that not only isolated 12(S)-HETE but also MDA-MB231 spheroids induced MLC2 phosphorylation

in LECs of the migratory-active rim zone of CCIDs (Figure 1F and Supplementary figure S1) and in pulmonary artery endothelial cells as prerequisite for transcellular migration (Khuon et al, 2010). Furthermore, it was shown that also MCF-7 spheroids activate MLC2 in LECs (Vonach et al, 2011).

12-HETER mediates 12(S)-HETE signal transduction to MLC2. Next, it was investigated whether 12-HETER expression was 
relevant for 12(S)-HETE-induced phosphorylation of MLC2 and for CCID formation. Therefore, LECs were transfected with siRNA against 12-HETER (si12-HETER), which significantly reduced the expression of 12-HETER protein (Figure 2A). The treatment with 12(S)-HETE induced the phosphorylation of MLC2 in control LECs (transfected with n.t.Co). In contrast, in si12-HETERtransfected LECs 12(S)-HETE treatment failed to induce phosphorylation of MLC2 (Figure 2B lanes 3 and 4) indicating that 12(S)-HETE induced the phosphorylation of MLC2 through 12-HETER. In addition, MDA-MB231 spheroid-induced CCID formation was significantly reduced $(\sim 30 \%)$ in si12-HETERtransfected LEC monolayers (Figure 2C). Therefore, 12-HETER contributes to 12(S)-HETE-induced MLC2 phosphorylation and CCID formation.

MLC2 phosphorylation and CCID formation is mediated via ROCK. Ser19 of MLC2 was shown to be phosphorylated by RHOassociated protein kinase (ROCK; Leung et al, 1996). To elucidate the connecting signalling components between MLC2 activation and 12-HETER expression LECs were pre-treated with the ROCK inhibitor Y27623, which suppressed constitutive and 12(S)-HETEinduced phosphorylation of MLC2 (Figure 3A). Furthermore, MDA-MB231-induced CCID formation was dose-dependently inhibited by increasing concentrations of Y27623 (Figure 3B). ROCK phosphorylates Thr696 of myosin phosphatase targeting subunit 1 (MYPT1), which is a negative regulator of MLC2 (Aburima et al, 2013). The phosphorylation of this amino acid is indicative for the inactivation of MYPT. Therefore, Thr696-MYPT phosphorylation results in a concomitant increase of Ser19-MLC2 phosphorylation (Xia et al, 2005). 12(S)-HETE induced the phosphorylation of MYPT in LECs (Figure 3A), whereas the pre-treatment of LECs with Y27623 (inhibiting ROCK) suppressed 12(S)-HETE-induced MYPT1 phosphorylation (Figure 3A lanes 3 and 4). Thus, ROCK and MYPT contributed to 12(S)-HETEtriggered phosphorylation of MLC2 and lymph endothelial barrier breaching. Another pathway culminating in MLC2 activation and microvascular barrier hyper-permeability and dysfunction was reported through myosin light chain kinase particularly in response to inflammatory mediators (Rigor et al, 2013).

MLC2 phosphorylation and CCID formation is mediated via RHO. RHO is the name given to the upstream activator of ROCK, which causes the unfolding of its kinase domain. To investigate whether RHO activity was required for 12(S)-HETE-induced MLC2 phosphorylation and for MDA-MB231-induced CCID formation, LECs were pre-treated with the specific RHO-GTPase inhibitor rhosin (Shang et al, 2012). This prevented the induction of MLC2 phosphorylation in 12(S)-HETE-treated LECs (Figure 4A) and CCID formation by MDA-MB231 spheroids significantly (Figure 4B). G-protein coupled receptor GPR130 was shown to induce RHO, ROCK and migration through activation of JAK1 (Sanz-Moreno et al, 2011). However, in MDA-MB231induced CCID formation of LECs JAK1 was not involved, as demonstrated by the specific small molecule JAK inhibitor pyridone P6, which had no influence on this process (Figure 4C).

A
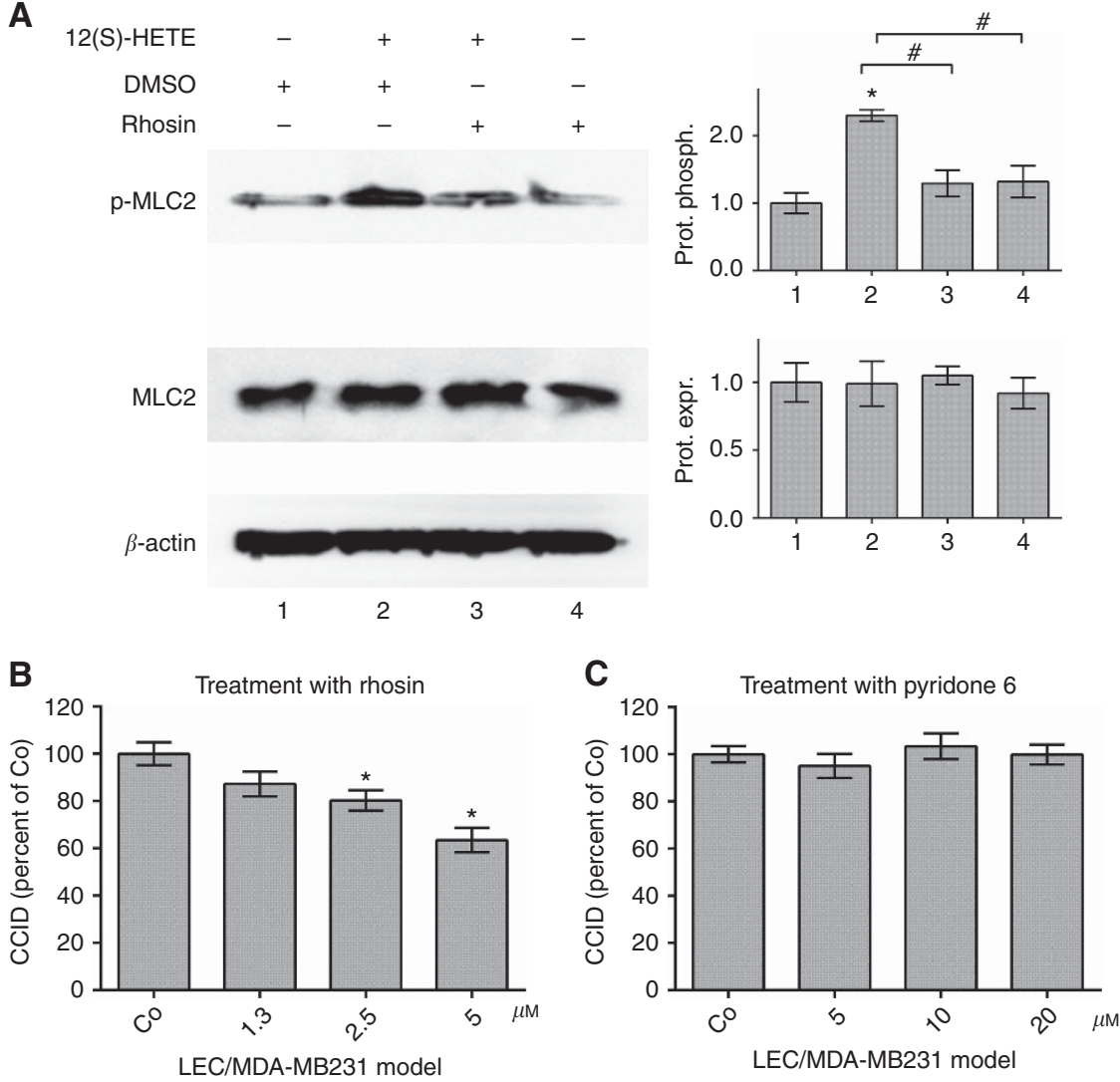

Figure 4. Inhibition of RHO-GTPase attenuates 12(S)-HETE-induced MLC2 phosphorylation and CCID formation. (A) Lymph endothelial cells were pre-treated with $10 \mu \mathrm{m}$ rhosin (RHO-GTPase inhibitor) or solvent (DMSO) for $1 \mathrm{~h}$ and then stimulated with 12 (S)-HETE for $15 \mathrm{~min}$, and relative protein phosphorylation (prot. phosph.) or protein expression (prot. expr.) was quantified by densitometry (three technical replicates). The numbers below the bar graphs refer to the respective treatment conditions indicated in the lanes of the blots. Non-targeting control (n.t.Co) was set to 1. (B) Confluent LECs were pre-treated with solvent (DMSO) or 1.3, 2.5 and $5 \mu \mathrm{m}$ rhosin or (C) 5, 10 and $20 \mu \mathrm{m}$ pyridone P6 (JAK inhibitor) for 30 min, and then MDA-MB231 spheroids were placed on top of LECs monolayers and co-incubated for $4 \mathrm{~h}$ when the areas of CCIDs were measured (27-34 replicates of three independent experiments). Error bars indicate means \pm s.e.m., and asterisks significance $(P<0.05$; $t$-test or ANOVA). 


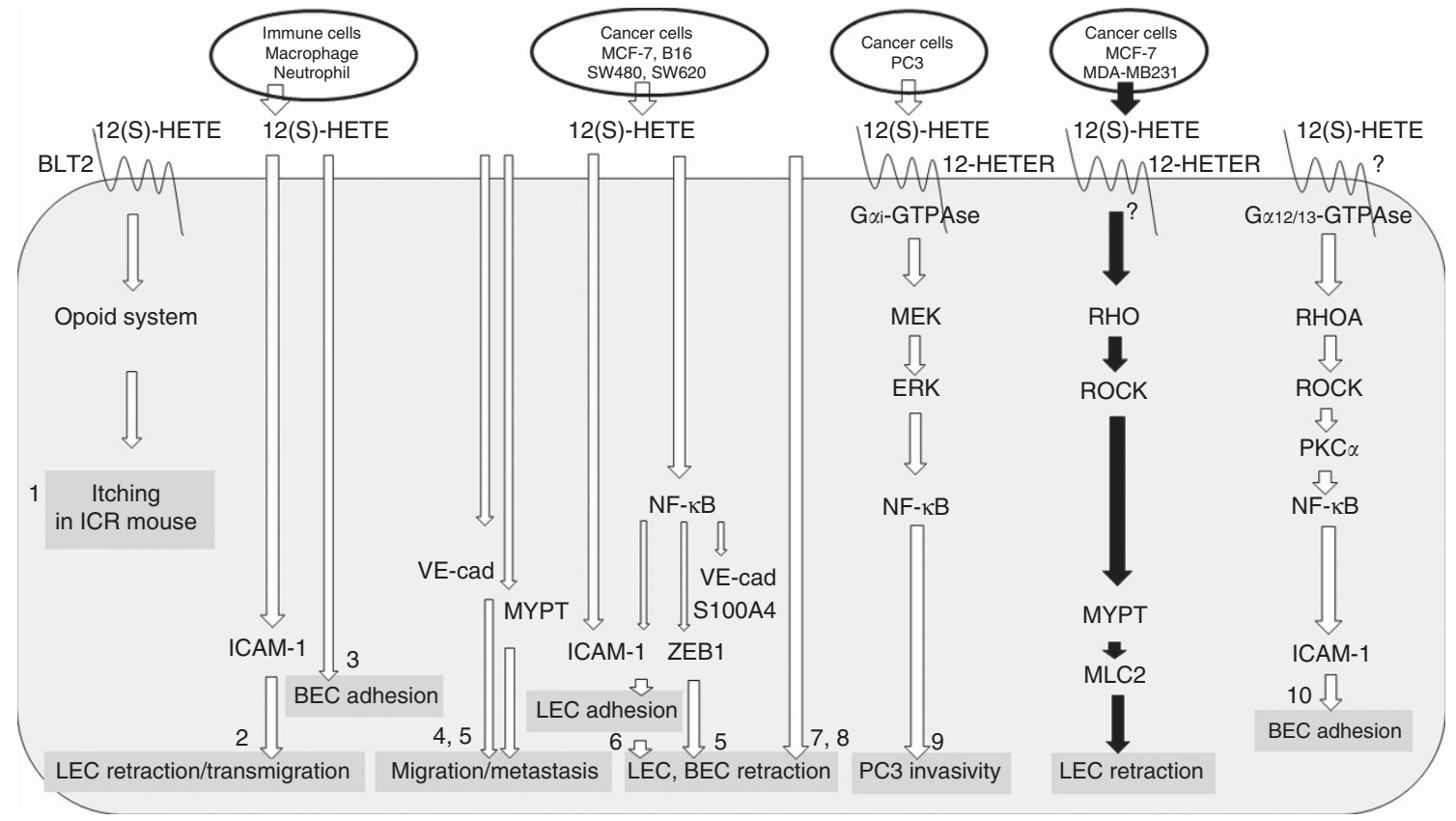

Figure 5. Schematic sketch outlining 12(S)-HETE-triggered signal transduction. 12(S)-HETE is secreted by immune- and cancer cells.

Various reports (a selection is listed by 1-10; see citations below) demonstrate the effects, which 12(S)-HETE elicits in endothelial cells (LEC: lymph endothelial cell; BEC: blood endothelial cell), or in PC3 prostate cancer cells. The cascades of signal transducing components that were discovered in these studies are shown. The details connected by black arrows depict the findings of this study. 12-HETER, high-affinity 12(S)-HETE receptor; BLT2, leukotriene B4 receptor 2 - low affinity 12(S)-HETE receptor; VE-cad, VE-cadherin. References: (1) Kim et al, 2008; (2) Rigby et al, 2015; (3) Wen et al, 2008; (4) Kerjaschki et al, 2011; (5) Vonach et al, 2011; (6) Viola et al, 2013; (7) Honn et al, 1994; (8) Uchide et al, 2007; (9) Guo et al, 2011; (10) Bolick et al, 2005.

Former studies demonstrated that the treatment of prostate carcinoma cells with 12(S)-HETE induced their invasivity, which depended on 12-HETER expression. This mechanism was sensitive to pertussis toxin indicating that the receptor signals through $\mathrm{G}_{\alpha \mathrm{i}^{-}}$ type GTPases (Guo et al, 2011). In contrast, $G_{\alpha 12 / 13}$-type GTPases and RHOA were shown to be responsible for the transduction of the 12(S)-HETE signal in mouse aortic endothelial cells (Bolick et al, 2005). This suggests that 12(S)-HETE-triggered signal transduction may be mediated through distinct trimeric GTPases depending on the cell type. A schematic sketch depicts 12(S)-HETE-induced signalling cascades and effects in recipient cells (Figure 5).

Whereas RHOA negatively regulates endothelial barrier function, RAC1 and CDC42 stabilise vascular barriers (Spindler et al, 2010). Currently, one clinical trial targeting the GTPases RAC and CDC42 with ketorolac (ovarian cancer; recruiting), and another trial targeting HMG-CoA (and also RAC and CDC42) with simvastatin in relapsed CCL (phase 1; completed, no data available), are the only cancer related studies, but there exist none that target RHO. There are two clinical trials targeting ROCK using AR-12286 and another two trials using fasudil (phase 2 and 3), but not in context with cancer treatment. Interestingly, one of the AR-12286 studies (phase 2, no data available) focusses on vascular function. No clinical trials target myosin, MYPT, MLC2 or 12-HETER (https://clinicaltrials.gov). The attempt to intervene on targets that reside high upstream of signalling cascades, such as RHO/RAC GTPAses, implicates that most of the downstream pathways that deviate from there are very likely affected as well. This may compromise the intended therapy due to severe side effects. Thus, hitting a downstream effector protein may provide a better concept largely avoiding undesired toxicity. Whether the unconventional intervention strategy to manipulate endothelial/ stromal response, as addressed in this in vitro investigation, supports conventional therapies at an early stage of disease is unpredictable and requires testing in vivo.
Conclusion. The present data propose that 12-HETER-RHOROCK-MYPT and MLC2 are involved in 12(S)-HETE-induced retraction of LECs and contribute to lymph endothelial disruption.

\section{ACKNOWLEDGEMENTS}

We wish to thank Toni Jäger for preparing the figures. CHN was supported by technology grant (TSA Doktorat) financed by the Austria Federal Ministry of Science and Research (BMFW) in frame of Asea Uninet. The work was supported by a grant of the Herzfeldeŕsche Family Foundation to GK.

\section{CONFLICT OF INTEREST}

The authors declare no conflict of interest.

\section{REFERENCES}

Aburima A, Wraith KS, Raslan Z, Law R, Magwenzi S, Naseem KM (2013) cAMP signaling regulates platelet myosin light chain (MLC) phosphorylation and shape change through targeting the RhoA-Rho kinase-MLC phosphatase signaling pathway. Blood 122(20): 3533-3545.

Bolick DT, Orr AW, Whetzel A, Srinivasan S, Hatley ME, Schwartz MA, Hedrick CC (2005) 12/15-lipoxygenase regulates intercellular adhesion molecule-1 expression and monocyte adhesion to endothelium through activation of RhoA and nuclear factor-kappaB. Arterioscler Thromb Vasc Biol 25(11): 2301-2307.

Guo Y, Zhang W, Giroux C, Cai Y, Ekambaram P, Dilly AK, Hsu A, Zhou S, Maddipati KR, Liu J, Joshi S, Tucker SC, Lee MJ, Honn KV (2011) Identification of the orphan $\mathrm{G}$ protein-coupled receptor GPR31 as a receptor for 12-(S)-hydroxyeicosatetraenoic acid. J Biol Chem 286: 33832-33840. 
Hamberg M, Samuelsson B (1974) Prostaglandin endoperoxides. Novel transformations of arachidonic acid in human platelets. Proc Natl Acad Sci USA 71(9): 3400-3404.

Honn KV, Tang DG, Grossi I, Duniec ZM, Timar J, Renaud C, Leithauser M, Blair I, Johnson CR, Diglio CA, Kimler VA, Taylor JD, Marnett LJ (1994) Tumor cell-derived 12(S)-hydroxyeicosatetraenoic acid induces microvascular endothelial cell retraction. Cancer Res 54(2): 565-574.

Kerjaschki D, Bago-Horvath Z, Rudas M, Sexl V, Schneckenleithner C, Wolbank S, Bartel G, Krieger S, Kalt R, Hantusch B, Keller T, NagyBojarszky K, Huttary N, Raab I, Lackner A, Krautgasser K, Schachner H, Kaserer K, Rezar S, Madlener S, Vonach C, Davidovits A, Nosaka H, Hämmerle M, Viola K, Dolznig H, Schreiber M, Nader A, Mikulits W, Gnant M, Hirakawa S, Detmar M, Alitalo K, Nijman S, Offner F, Maier TJ, Steinhilber D, Krupitza G (2011) Lipoxygenase mediates invasion of intrametastatic lymphatic vessels and propagates lymph node metastasis of human mammary carcinoma xenografts in mouse. J Clin Invest 121(5): 2000-2012.

Khuon S, Liang L, Dettman RW, Sporn PH, Wysolmerski RB, Chew TL (2010) Myosin light chain kinase mediates transcellular intravasation of breast cancer cells through the underlying endothelial cells: a three-dimensional FRET study. J Cell Sci 123(pt 3): 431-440.

Kim HJ, Kim DK, Kim H, Koh JY, Kim KM, Noh MS, Lee S, Kim S, Park SH, Kim JJ, Kim SY, Lee CH (2008) Involvement of the BLT2 receptor in the itch-associated scratching induced by 12-(S)-lipoxygenase products in ICR mice. Br J Pharmacol 154(5): 1073-1078.

Klampfl T, Bogner E, Bednar W, Mager L, Massudom D, Kalny I, Heinzle C, Berger W, Stättner S, Karner J, Klimpfinger M, Fürstenberger G, Krieg P, Marian B (2012) Up-regulation of 12(S)-lipoxygenase induces a migratory phenotype in colorectal cancer cells. Exp Cell Res 318(6): 768-778.

Leung T, Chen XQ, Manser E, Lim L (1996) The p160 RhoA-binding kinase ROK alpha is a member of a kinase family and is involved in the reorganization of the cytoskeleton. Mol Cell Biol 16(10): 5313-5327.

Murata K, Noda SE, Oike T, Takahashi A, Yoshida Y, Suzuki Y, Ohno T, Funayama T, Kobayashi Y, Takahashi T, Nakano T (2014) Increase in cell motility by carbon ion irradiation via the Rho signaling pathway and its inhibition by the ROCK inhibitor Y-27632 in lung adenocarcinoma A549 cells. J Radiat Res 55(4): 658-664.

Nguyen CH, Senfter D, Basilio J, Holzner S, Stadler S, Krieger S, Huttary N, Milovanovic D, Viola K, Simonitsch-Klupp I, Jäger W, de Martin R, Krupitza G (2015) NF- $\kappa B$ contributes to MMP1 expression in breast cancer spheroids causing paracrine PAR1 activation and disintegrations in the lymph endothelial barrier in vitro. Oncotarget 6(36): 39262-39275.

Rabinovitch H, Durand J, Rigaud M, Mendy F, Breton JC (1981) Transformation of arachidonic acid into monohydroxy-eicosatetraenoic acids by mouse peritoneal macrophages. Lipids 16(7): 518-524.

Rigby DA, Ferguson DJ, Johnson LA, Jackson DG (2015) Neutrophils rapidly transit inflamed lymphatic vessel endothelium via integrin-dependent proteolysis and lipoxin-induced junctional retraction. J Leukoc Biol 98(6): 897-912.

Rigor RR, Shen Q, Pivetti CD, Wu MH, Yuan SY (2013) Myosin light chain kinase signaling in endothelial barrier dysfunction. Med Res Rev 33(5): 911-933.

Sanz-Moreno V, Gaggioli C, Yeo M, Albrengues J, Wallberg F, Viros A, Hooper S, Mitter R, Féral CC, Cook M, Larkin J, Marais R, Meneguzzi G, Sahai E, Marshall CJ (2011) ROCK and JAK1 signaling cooperate to control actomyosin contractility in tumor cells and stroma. Cancer Cell 20(2): 229-245.

Senfter D, Holzner S, Kalipciyan M, Staribacher A, Walzl A, Huttary N, Krieger S, Brenner S, Jäger W, Krupitza G, Dolznig H, Mader RM (2015) Loss of miR-200 family in 5-fluorouracil resistant colon cancer drives lymphendothelial invasiveness in vitro. Hum Mol Genet 24(13): 3689-3698.

Shang X, Marchioni F, Sipes N, Evelyn CR, Jerabek-Willemsen M, Duhr S, Seibel W, Wortman M, Zheng Y (2012) Rational design of small molecule inhibitors targeting RhoA subfamily Rho GTPases. Chem Biol 19(6): 699-710.

Spindler V, Schlegel N, Waschke J (2010) Role of GTPases in control of microvascular permeability. Cardiovasc Res 87(2): 243-253.

Sun J, Zhang D, Zheng Y, Zhao Q, Zheng M, Kovacevic Z, Richardson DR (2013) Targeting the metastasis suppressor, NDRG1, using novel iron chelators: regulation of stress fiber-mediated tumor cell migration via modulation of the ROCK1/pMLC2 signaling pathway. Mol Pharmacol 83(2): 454-469.

Teichmann M, Kretschy N, Kopf S, Jarukamjorn K, Atanasov AG, Viola K, Giessrigl B, Saiko P, Szekeres T, Mikulits W, Dirsch VM, Huttary N, Krieger S, Jäger W, Grusch M, Dolznig H, Krupitza G (2014) Inhibition of tumour spheroid-induced prometastatic intravasation gates in the lymph endothelial cell barrier by carbamazepine: drug testing in a 3D model. Arch Toxicol 88(3): 691-699.

Uchide K, Sakon M, Ariyoshi H, Nakamori S, Tokunaga M, Monden M (2007) Cancer cells cause vascular endothelial cell (vEC) retraction via 12(S)HETE secretion; the possible role of cancer cell derived microparticle. Ann Surg Oncol 14(2): 862-868.

Viola K, Kopf S, Huttary N, Vonach C, Kretschy N, Teichmann M, Giessrigl B, Raab I, Stary S, Krieger S, Keller T, Bauer S, Hantusch B, Szekeres T, de Martin R, Jäger W, Mikulits W, Dolznig H, Krupitza G, Grusch M (2013) Bay11-7082 inhibits the disintegration of the lymphendothelial barrier triggered by MCF-7 breast cancer spheroids; the role of ICAM-1 and adhesion. Br J Cancer 108(3): 564-569.

Vonach C, Viola K, Giessrigl B, Huttary N, Raab I, Kalt R, Krieger S, Vo TP, Madlener S, Bauer S, Marian B, Hämmerle M, Kretschy N, Teichmann M, Hantusch B, Stary S, Unger C, Seelinger M, Eger A, Mader R, Jäger W, Schmidt W, Grusch M, Dolznig H, Mikulits W, Krupitza G (2011) NF-кB mediates the 12(S)-HETE-induced endothelial to mesenchymal transition of lymphendothelial cells during the intravasation of breast carcinoma cells. Br J Cancer 105(2): 263-271.

Wculek SK, Malanchi I (2015) Neutrophils support lung colonization of metastasis-initiating breast cancer cells. Nature 528(7582): 413-417.

Wen Y, Gu J, Vandenhoff GE, Liu X, Nadler JL (2008) Role of 12/15lipoxygenase in the expression of MCP-1 in mouse macrophages. Am J Physiol Heart Circ Physiol 294(4): H1933-H1938.

Xia D, Stull JT, Kamm KE (2005) Myosin phosphatase targeting subunit 1 affects cell migration by regulating myosin phosphorylation and actin assembly. Exp Cell Res 304(2): 506-517.

This work is published under the standard license to publish agreement. After 12 months the work will become freely available and the license terms will switch to a Creative Commons AttributionNonCommercial-Share Alike 4.0 Unported License.

Supplementary Information accompanies this paper on British Journal of Cancer website (http://www.nature.com/bjc) 